\title{
Women's Perceptions of Future Risk After Low-Energy Fractures at Midlife
}

Lynn M. Meadows, PbD

Linda Mrkonjic, MD, FRCFS, MSc

Laura Lagendyk, MSc

University of Calgary, Alberta, Canada
Conflicts of interest: none reported

\section{CORRESPONDING AUTHOR}

Lynn M. Meadows, PhD

Department of Family Medicine

University of Calgary

3330 Hospital Dr NW

Calgary Alberta, Canada T2N 4N1

meadows@ucalgary.ca

\begin{abstract}
PURPOSE Low-energy fractures experienced by women at midlife and beyond place them at increased risk of future fractures and may be early indicators of low bone density. We report here on women's postfracture narratives to provide insight into how family physicians might tailor their messages to patients in communicating risk.
\end{abstract}

METHODS An interview guide was used in face-to-face interviews with women aged 40 years and older. Patients were asked to describe their fracture experience and recovery during the subsequent year. Interviews were audiorecorded and transcribed verbatim. Analysis was done initially using an immersion-crystallization approach.

RESULTS Twenty-two women participated in this research. The analysis showed women's reactions to information about their risk fell into 3 groups. The first took a laissez faire approach, preferring to wait and see what the future held. The second group recognized some of the things they should be doing but were inconsistent in maintaining changes or seeking relevant information. The third group saw information about future risk as salient and important to their daily lives. They actively sought out information, including discussions with their family physicians.

CONCLUSIONS Discovering whether patients have had an injury and, if so, how they perceive future risk is important because the invisibility of this health hazard calls for vigilance early on in women's lives. Family physicians can help patients move from perceiving the fractures as isolated accidents to understanding them as indicators of future risk by discussing the importance of bone health in the short and long term.

Ann Fam Med 2005:3:64-69. DOI: 10.1370/afm.258.

\section{INTRODUCTION}

U ntil recently the focus on bone health for women tended to be on osteoporosis, a condition of established chronic disease and a source of considerable public health cost. ${ }^{1.8}$ In Canada, 1 in 4 women and 1 in 8 men aged 50 years and older have osteoporosis. ${ }^{9}$ The risk of low-energy fractures is substantial: at a population level women have a 1 in 6 lifetime risk of hip fractures, as compared with a 1 in 9 risk of developing breast cancer. ${ }^{2,10,11}$ Recent research in Canada projects an annual total cost for femoral fractures alone (about three quarters occurring in women) at $\$ 10$ billion, rising to $\$ 20$ billion if osteoporotic fractures are included. ${ }^{12}$ Aside from economic costs, the "quality of life impact of hip, wrist and vertebral fractures" is often overlooked. ${ }^{5}$ Earlier research by our team has shown that the short- and long-term sequelae of extremity fractures, including time off work, the need for support for activities of daily living, and permanent loss of function and disfigurement, ${ }_{1}^{13}$ are great, even in the absence of established disease.

Prevention, early detection, and cost-effective treatment are possible and recommended to save pain, suffering, and health care costs of osteoporosis and related fractures. ${ }^{3-5}$ Published research on fractures, however, 
has a largely clinical focus (eg, on the underlying bone architecture or the biomechanics of bone-fixation techniques) rather than investigating health implications and prevention. At a population level little attention has been paid to the potential for preventive measures after low-energy fractures* occur and before osteoporosis develops. Follow-up for fractures is inconsistent, and there is a lack of clarity about who should initiate follow-up and when. ${ }^{14}$

Currently the role of family physicians in relation to fragility fracture prevention is hampered by 2 factors. First, there is inconsistent transfer of information from the acute care setting where often the fracture is treated, so the family doctor may not be aware that a patient suffered a fracture. Fracture care is often assumed to be the domain of other physicians rather than family or general physicians, with clinical treatment ending when the bone is healed. ${ }^{15}$ Second, patients may not perceive themselves as being at increased risk of future fractures subsequent to a low-energy fracture. Not only do physicians need to be aware that their patients are at risk, but the patients themselves must be open to information about risk and prevention before dialogue regarding prevention can be initiated. We report here on a study of women's experiences of fractures and present data in which women reflect on their perceived fracture risk after having suffered a low-energy fracture at midlife (ie, 40 years and beyond). The information that follows can be used by family physicians to recognize patients who may be at risk for future fractures and provide insight into communicating clinical prevention-related information to these patients. We also want to raise awareness of the potential for using fractures at midlife and beyond as triggers for investigation of bone health and prevention of future fractures. Because fracture predicts fracture, ${ }^{14}$ it is essential that this opportunity for intervention be recognized and acted upon as a necessary step in prevention.

\section{Conceptual Background}

Our analysis is guided conceptually by past research related to perceptions of health risk, ${ }_{1}^{16}$ decision making related to health, ${ }^{17}$ and the rationale used by lay persons to decide who and how persons are at risk for threats to their health. ${ }^{18-22}$ This work suggests that although some may be aware of risk of illness or injury, they are balancing their personal perceived risk against the perceived benefit of taking a preventive action. ${ }^{16}$ A person understands risk at 2 levels: the collective (population health) and individual. This dual consciousness ${ }^{16}$ means that hazards that are not very visible go unattended (eg, the hidden nature of poor bone architecture).

Furthermore, persons in their everyday lives use cul- tural systems of explanation or accountability to address questions of why a particular misfortune occurs and to whom. ${ }^{21}$ For example, a person can readily identify candidates for a heart attack, describing them as "big, fat wheezy blokes" or "a walking heart attack waiting to happen." ${ }^{\prime 21}$ This lay epidemiologic description complements the scientific epidemiologic description that concentrates on cause and distribution of chronic disease. ${ }^{21}$

\section{Research Team}

Our research team has a shared passion for women's health and commitment to foster shared care postfracture to enhance opportunities for prevention of future fractures. Our population of interest is women at midlife, defined by us as between the ages of 40 and 65 years. Although our respective training in sociology and mixed methods (Meadows), orthopedic trauma surgery and epidemiology (Mrkonjic), and social work and health (Lagendyk) bring their own disciplinary perspectives, our collaboration has led to research that transcends these individual orientations while still raising questions that arise from them. We continue to develop our program of research to address new issues.

\section{METHODS}

This study was part of a series of studies. Our Conjoint Health Research Ethics Board granted ethical approval. Patients routinely grant permission to the clinical author (Mrkonjic) to contact them for participation in future research projects and stores this information in a secure database. This database was used to select midlife women with fractures who were then contacted and invited to participate in the study. When they agreed, screening confirmed their age and their English competency. No other screening criteria were used. At the time of the interviews, consent forms were reviewed and signed by the participating women.

Our experienced research assistants received training specific to the project. They conducted face-to-face in-depth interviews using a guide that was modified as new issues or questions of confirmation or disconfirmation arose during the interviews. Data collection continued until no new information emerged. ${ }^{23,24}$ Interviews were audiorecorded and transcribed verbatim. ${ }^{\dagger}$ Initially 3 members of the research team immersed themselves in the data through a process of reading and rereading the transcripts to identify initial codes. These codes were discussed and solidified, then used to explore relationships and contingencies. Further analysis produced key themes that all team members agreed

\footnotetext{
* From a standing height or similar trauma. ${ }^{11}$

† Participants were assigned an identification code on tapes and transcripts to maintain anonymity.
} 
appeared throughout the data. As a final step in the process, we searched for disconfirming evidence and tested interpretations against alternative understandings. ${ }^{25,26}$ Data summary, analysis, and interpretation were aided by the use of the QSR N6 program. ${ }^{27}$

Throughout the study tenure several strategies were used to ensure the rigor of the outcome. We approached the study design within the context of a full review of the relevant literature; were explicit about our disciplinary biases, previous knowledge, and expected outcomes ${ }^{24}$; sampled until no new information emerged ${ }^{24} ;$ and made decisions throughout the recruitment and data collection process based on principles of sound qualitative research. ${ }^{26,28}$ Study rigor was enhanced by having multiple team members do data coding and participate in discussions regarding interpretation, and by the search for disconfirming evidence and competing explanations. ${ }^{28,29}$

\section{RESULTS}

Twenty-two in-depth individual interviews were conducted, on average 1 year after the fracture. Women's responses to the low-energy fractures during the initial phases of recovery were relatively homogeneous. Women were surprised that their accident resulted in a fracture and explained their fracture by explaining their fall. Women admitted that before their fractures they had assumed that breaking a bone was "no big deal." Women described the fracture experience as "just real tough" and said, "I don't ever want to go through it again"; that "once is enough"; and that "I wouldn't wish it on anybody, just because you're so incapacitated." Only a few women assessed themselves as "back to normal."

Despite the shared experience of recovery, women's knowledge of bone health and reactions related to bone health and perception of future risk varied widely. Although best conceived as a continuum, for ease of discussion we present these variations in 3 groups, each with identifiable characteristics. Table 1 displays a summary of women's perspectives that characterize these groups.

\section{Table 1. Patients Perspectives of Future Fracture Risk}

\begin{tabular}{|c|c|c|c|c|}
\hline \multirow[b]{2}{*}{ Group } & \multicolumn{4}{|c|}{ Patients Perspectives of Future Fracture Risk } \\
\hline & $\begin{array}{l}\text { Cause of } \\
\text { Fracture }\end{array}$ & Pertinence & $\begin{array}{l}\text { Prevention } \\
\text { Measures }\end{array}$ & $\begin{array}{l}\text { Family } \\
\text { Physician Role }\end{array}$ \\
\hline Wait and see & Accident & Isolated event & None & None \\
\hline $\begin{array}{l}\text { I know I should } \\
\text { but ... }\end{array}$ & Accident & Questions raised & Ad hoc & $\begin{array}{l}\text { One source of } \\
\text { information } \\
\text { among many }\end{array}$ \\
\hline $\begin{array}{l}\text { No more } \\
\text { fractures! }\end{array}$ & $\begin{array}{l}\text { Compromised } \\
\text { bone }\end{array}$ & Action taken & $\begin{array}{l}\text { Information } \\
\text { management } \\
\text { plan }\end{array}$ & Consulted \\
\hline
\end{tabular}

\section{"I'll Just Wait and See"}

For a number of women the fracture was experienced as an isolated event with little if any meaning beyond waiting for a broken bone to heal. Despite their fractures, communication with their physicians about bone health was irrelevant for them, and it was not a topic about which they sought information. Women showed limited knowledge about bone health. A typical reply when questioned directly about osteoporosis was "some people get a hunched back." Risk for osteoporosis was associated with "shrinking grandmothers." The idea of being at personal risk had not occurred to this group, and they questioned the relevance of bone mineral density (BMD) testing to them as individuals. One avid runner who had multiple fractures before the one pertinent to our study procrastinated on her physician's recommendation for BMD testing and was interested in bone health only as it related to running proficiency. Others had a BMD test, but had no idea of the results.

Among this group, fractures were blamed on circumstances. Some women even believed "chances are it will never happen again," exhibiting little awareness that fractures were potential markers of poor bone health. Information about bone health and osteoporosis was neither retained nor did it provide a stimulus to change. Some women reported "eating more vegetables" or "taking supplements," such as calcium for muscle cramps, and "doubling up on magnesium ... but I don't know if I should continue ... because I'm healed." Their confusion about supplement use did not lead them to seek their physician's advice to clarify these issues.

\section{"I Know I Should But ..."}

Although the second group displayed a wider range of information about bone health and osteoporosis, it was evident that the meaning and importance of that information were often unclear. They tended to gain bone health knowledge passively (eg, through colleagues in a chiropractic practice), noting multiple sources of information that chanced their way (eg, professional advice, media or pharmaceutical company brochures). Family physicians were only one source of information among many. When different treatment options were suggested by family physicians and orthopedic surgeons, these women rarely sought clarification of the issues from their family doctors.

This group minimized BMD test results, reflected in one woman's comment that "everyone has it [osteoporosis] a bit." Behavior changes were inconsistent, exemplified by one woman who 
planned to "just have an ounce of tofu every night ... then I fell off the wagon." These women were unaware that successful bone health promotion strategies required long-term consistent action and that improvement might be invisible. For them, risk reduction was associated with avoiding the circumstances in which their fractures had occurred. Health-promoting behavior was a hit-and-miss affair, and knowledge related to osteoporosis and bone health that was direct and personalized failed to be seen as relevant.

Patient: I tried to start walking a bit. I baven't done as much as I should. Um ... but I should do a lot more. Yeab, I eat yogurt.

Interviewer: ... in terms of your overall quality of life, how do you think having $a$, the diagnosis of "mild osteoporosis" affected that?

Patient: It basn't changed at all.

\section{"No More Fractures!"}

Women in our third group had assumed before their injury that advanced age was a primary criterion for osteoporosis. In our interviews, however, these women framed their fractures as events that challenged their assumptions about their own bone health. One woman was the sole interviewee to identify immediately the incongruence between her fracture and its circumstances, surprised that her tibia had shattered from "what I would consider a slight fall."

These women confidently reported accurate information about bone health and osteoporosis, including a wide range of risk factor prevention and treatment strategies. They actively sought out information, naming multiple sources they had investigated to improve their knowledge: libraries, Internet sites, and physicians. One woman noted, "I took the Osteoporosis Self-Management Course." The women often reported and clarified information they had found in collaboration with their physicians. Notably some of these women were actively raising public awareness of osteoporosis and bone health issues (eg, speaking to friends, participating in osteoporosis information groups, lobbying government to cover osteoporosis medication). The importance of spreading the word to younger people was a common theme.

Unlike other women in the study, when evidence of BMD testing challenged their assumptions of bone strength and future risk, they moved past rationalization to acceptance and initiated communication with their family physicians and proactive and consistent participation in their own bone health care. One 50year-old woman noted, "The bones in my hips are those of about a 65 year old ... this isn't good." They realized that treatment and testing was required long term to make sure "to keep your guidelines (of calcium and bone density)."
All women in this group clearly recognized they were at increased risk for future fracture and understood their fracture as a potential marker for compromised bone health. They spoke in the first person, using phrases like being afraid to fall "in case I fracture my bones" and "I have an increased risk ... of breaking something." Moreover, they clearly connected their bone health promotion activities to reducing the risk for future fractures.

Patient: I'm fearful of falling. Of any fall causing any breakage... And as long as I do the bone-building activities, the core building and strengthening of the muscles, bopefully that'll belp... to ensure no more fractures [emphasis in original].

\section{DISCUSSION}

The individual interviews of 22 women who had experienced an extremity fracture in the previous year suggest that only a minority of them understand and apply information about bone health and increased fracture risk to their own situation. For most women information about sustained pharmaceutical treatments, supplements (eg, calcium or vitamin D), or other preventive measures, such as weight-bearing exercise or BMD testing, are not understood in a context of personal risk. The way these women are framing their injury may be similar to how patients in an earlier study who had suffered a hip fracture in their senior years (mean age, 80 years) framed their injury - in a mechanistic fashion, that is, fall leads to fracture, as a way of "denying that their bodies are degenerating." ${ }^{\text {"30 }}$

Although previous research on women and healthrelated decision making suggests women are eager to share decision making about a number of health conditions, ${ }^{17}$ the effective transfer of risk-related information about less high profile but no less threatening conditions remains a challenge. In a clinical encounter the teachable moment related to fracture risk might be compromised if the family physician is not aware a fracture has occurred, and if patients do not bother to mention a fracture because they do not understand future fracture risks. Our data suggest that stereotypical perceptions of osteoporosis as affecting only those who are elderly and frail not only endure but exist for many in a context of limited knowledge of bone health and risks. ${ }^{31}$ Only a minority of women in our study recognized their low-energy fracture as an indicator of increased susceptibility for future fractures and committed themselves to long-term prevention.

Earlier research has shown that patients' illness stories illustrate their explanatory models for how the event occurred ${ }^{22}$ and may even play a role in their recovery. ${ }^{30}$ Borkan et $\mathrm{al}^{30}$ suggest that these injury nar- 
ratives may be a prognostic tool that helps explain recovery from hip fractures. Future studies will benefit not only from exploring whether women's perceptions of future fracture risk as explained in our study are static or change with time but also from examining the role of family physicians in that process. A first step may be asking patients immediately after the fracture about their assessment of future risk.

Women at risk for future fractures are not likely to follow treatment plans if the issue lacks salience for them. Recent research ${ }^{32}$ has illustrated the power of using the transtheoretical mode ${ }^{33}$ as a guide to communication regarding intimate partner violence. Others have shown that patients' perceptions of potential health consequences were facilitated by a conversion experience, ie, a crucial event that suddenly rendered health information pertinent. ${ }^{34}$ The data in our study suggest the key for clinical communication of fracture risk may better lie in guiding women toward a conversion experience.

This study is limited by a focus on data from women who experienced fractures without comparing physicians' reports of information shared with patients. Although we are confident of our preliminary model of women's reactions to prevention information, further research is required to test it over time and prospectively. We need to know more about how those patients who hear and act on information relevant to their health are different from those who do not. Future research needs to explore precisely what information is being conveyed and why many women are not acting upon it.

\section{CONCLUSIONS}

Recent research and theorizing in primary care suggest that an important influence on illness outcomes is the healing relationship between a patient and those with whom she interacts during an illness experience. ${ }^{35}$ With limitless time and resources, a condition can be addressed using a full program of treatment options that are mutually agreed upon through dialogue between the clinician and patient. Given the realities of limited time and resources, assessing patients' semantics as they describe their fractures may provide immediate insight as to the most effective manner of presenting accessible prevention-related information to the individual patient in a teachable moment.

Communication of information to patients about their health continues to be a challenge for family physicians and other health care professionals. ${ }^{32,34}$ Regularly asking questions about injuries treated outside family practice may help uncover these critical incidents. Physicians might be cued to women's depersonalization of postfracture risk by their patients' explanations for the fracture (eg, "it was just an accident ${ }^{\prime \prime}$, vague statements about preventive measures (eg, "sure, I eat yogurt") or disinterest in further investigation (eg, "no I haven't had time to get that BMD, I'm better now"). Patients who personalize their injury through recognizing that "I am at increased risk" or "I broke my bone" illustrate use of "I" knowledge, the "reflective accumulation of particular experiences in a particular body." 35 This knowledge may be an indicator of their openness to discussion of their injury and implications for prevention

For both the midlife public at risk for future fractures and even chronic debilitating disease and the family physicians who are challenged with case findings, the invisible hazard of fragile bones at early stages in deterioration suggests this population should receive special attention regardless of whether signs of deterioration are visible.

To read or post commentaries in response to this article, see it online at http://www.annfammed.org/cgi/content/full/3/1/64.

Key words: Fractures/prevention $\varepsilon$ control; osteoporosis; primary health care; women's health; middle aged; integration of health and health care; health education; health promotion, qualitative research

Submitted October 8, 2003; submitted, revised, June 21, 2004; accepted June 25, 2004.

Funding support: This research was supported through funding from the Alberta Heritage Foundation for Medical Research Health Research Fund, the Shopper's Drug Mart Professorship in Women's Health, and The McCaig Foundation.

Acknowledgments: We thank those who shared their experiences with us, our research assistants M. Gowans and D. Sluchinski, and the editor and reviewers for their insightful comments. We also wish to thank Kathy Dirk for her exemplary editing.

\section{References}

1. Clinical practice guidelines for the diagnosis and management of osteoporosis. Scientific Advisory Board, Osteoporosis Society of Canada. CMAJ. 1996;155:1113-1133.

2. Brown JP, Josse RG. 2002 clinical practice guidelines for the diagnosis and management of osteoporosis in Canada. CMAJ. 2002;167(10 Suppl):S1-S34.

3. Cummings SR, Melton LJ. Epidemiology and outcomes of osteoporotic fractures. Lancet. 2002;359:1761-1767.

4. Khan A. Advances in osteoporosis therapy. 2003 update of practical guidelines. Can Fam Physician. 2003;49:441-447.

5. Melton LJ III, Thamer M, Ray NF, et al. Fractures attributable to osteoporosis: report from the National Osteoporosis Foundation. J Bone Miner Res. 1997;12:16-23.

6. Murray TM. Prevention and management of osteoporosis: consensus statements from the Scientific Advisory Board of the Osteoporosis Society of Canada. 4. Calcium nutrition and osteoporosis. CMAJ. 1996;155:935-939.

7. Ray NF, Chan JK, Thamer M, Melton LJ III. Medical expenditures for the treatment of osteoporotic fractures in the United States in 1995: report from the National Osteoporosis Foundation. J Bone Miner Res. $1997 ; 12: 24-35$. 
8. Watts NB. Postmenopausal osteoporosis. Obstet Gynecol Surv. 1999;54:532-538.

9. Clinical practice guidelines for the diagnosis and management of osteoporosis. Scientific Advisory Board, Osteoporosis Society of Canada. CMAJ. 1996;155:1113-1133.

10. Cummings SR, Black DM, Rubin SM. Lifetime risks of hip, Colles', or vertebral fracture and coronary heart disease among white postmenopausal women. Arch Intern Med. 1989;149:2445-2448.

11. Melton LJ III. Who has osteoporosis? A conflict between clinical and public health perspectives. J Bone Miner Res. 2000;15:2309-2314.

12. Lorrain J, Paiement G, Chevrier N, et al. Population demographics and socioeconomic impact of osteoporotic fractures in Canada. Menopause. 2003;10:228-234.

13. Meadows LM, Mrkonjic L. Breaking - bad news: women's experiences of fractures at midlife. Can J Public Health. 2003;94:427-430.

14. McLellan AR. Identification and treatment of osteoporosis in fractures. Curr Rheumatol Rep. 2003;5:57-64.

15. Jaglal SB, Carroll J, Hawker G, et al. How are family physicians managing osteoporosis? Qualitative study of their experiences and educational needs. Can Fam Physician. 2003;49:462-468.

16. Ballard K. Understanding risk: women's perceived risk of menopause-related disease and the value they place on preventive hormone replacement therapy. Fam Pract. 2002;19:591-595.

17. Brown JB, Carroll J, Boon H, Marmoreo J. Women's decision-making about their health care: views over the life cycle. Patient Educ Couns. 2002;48:225-231.

18. Clark AM. Treatment decision-making during the early stages of heart attack: a case for the role of body and self in influencing delays. Sociol Health IIln. 2001;23:425-446.

19. Hunt K, Davison C, Emslie C, Ford G. Are perceptions of a family history of heart disease related to health-related attitudes and behaviour? Health Educ Res. 2000;15:131-143.

20. Meadows LM, Thurston WE, Berenson CA. Health promotion and preventive measures: interpreting messages at midlife. Qual Health Res. 2001;11:450-463.

21. Davison C, Smith GD, Frankel S. Lay epidemiology and the rationality of responses to health education. Br J Gen Pract. 1991;41:428-430.

22. Kleinman A. Patients and Healers in the Context of Culture: An Exploration of the Borderland Between Anthropology, Medicine and Psychiatry. Los Angeles, Calif: University of California Press; 1980
23. Morse JM. The significance of saturation. Qual Health Res. 1995;5: 147-149.

24. Meadows LM, Morse JM. Constructing evidence within the qualitative project. In: Morse JM, Swanson JM, Kuzel A, eds. The Nature of Qualitative Evidence. Thousand Oaks, Calif: Sage Publications; 2001:187-200.

25: Borkan JM. Immersion / crystallization. In: Crabtree BF, Miller WL, eds. Doing Qualitative Research. Thousand Oaks, Calif: Sage Publications; 1999:179-194.

26. Meadows LM, Verdi AJ, Crabtree BF. Keeping up appearances: using qualitative methods in dental research. J Dent Educ. 2003;67:981-990.

27. Meadows LM, Dodendorf DM. Data management and interpretation - using computers to assist. In: Crabtree BF, Miller WL, eds. Doing Qualitative Research. Thousand Oaks, Calif: Sage Publications: 1999:195-218.

28. Crabtree BF, Miller WL. Using codes and code manuals: a template organization style of interpretation. In: Crabtree BF, Miller WL, eds, Doing Qualitative Research. Thousand Oaks, Calif: Sage Publications; 1999:163-178

29. Denzin NK. Interpretive Interactionism. Newbury Park, Calif: Sage Publications: 1989.

30. Borkan JM, Quirk M, Sullivan M. Finding meaning after the fall: injury narratives from elderly hip fracture patients. Soc Sci Med. 1991:33:947-957.

31. Backett-Milburn K, Parry O, Mauthner N. 'I'll worry about that when it comes along': osteoporosis, a meaningful issue for women at midlife? Health Educ Res. 2000;15:153-162.

32. Zink T, Elder N, Jacobson J, Klostermann B. Medical management of intimate partner violence considering the stages of change: precontemplation and contemplation. Ann Fam Med. 2004;2:231-239.

33. Prochaska JO, DiClemente CC, Norcross JC. In search of how people change. Applications to addictive behaviors. Am Psychol. 1992:47:1102-1114.

34. O'Connor PJ, Crabtree BF, Yanoshik MK. Differences between diabetic patients who do and do not respond to a diabetes care intervention: a qualitative analysis. Fam Med. 1997;29:424-428.

35. Miller WL, Crabtree BF, Duffy MB, Epstein RM, Stange KC. Research guidelines for assessing the impact of healing relationships in clinical medicine. Altern Ther Health Med. 2003;9(3 Suppl):A80-A95. 